\title{
USER-CENTERED APPROACH TO PRODUCT DESIGN FOR PEOPLE WITH VISUAL IMPAIRMENTS
}

\author{
Monika Rastovac ${ }^{1}$ (D), Jurica Dolić 2 (D), Jesenka Pibernik ${ }^{2}$ (D), Lidija Mandić 2 (i) \\ ${ }^{1} Q$-Bit d.o.o., Zagreb, Croatia \\ ${ }^{2}$ University of Zagreb, Faculty of Graphic Arts, Zagreb, Croatia
}

\begin{abstract}
The aim of this research was to investigate the application of the user-centred design process to the design and development of a product and it's packaging suitable for people with visual impairments. The product and packaging had to be accessible to stakeholders on both sides - not only to visually impaired end users but also to the workers with visual impairments in the production process. The accessibility features had to function in conjunction with other presentation and functional requirements of the product and packaging. In order to adapt the design for people with visual impairments, research of optimal design process was conducted using combination of contextual design with other user-centred methods. Rapid prototyping was used to create full-scale physical packaging models and product moulding tools for evaluation. Additional subjective evaluation using semantic differential was carried on users without visual impairments to establish the perception of pragmatic and hedonic quality of the packaging.
\end{abstract}

Key words: packaging, product design, visual impairment, Braille, user-centred Design, contextual design

\section{INTRODUCTION}

User-Centred Design (UCD), which is a subset of Human-Centred Design (HCD), is an approach to design of interactive products in which the deep understanding of users' needs and potentials presents a key factor for design decisions throughout the design process. With the ever-rising demands and expectations from the consumers in the competitive markets, employing UCD approach to product development has become a necessity rather than a choice. It is particularly important to include users when designing accessible products (Alzuhair et al, 2014). In many cases, visually impaired users have significantly different mental models than users without impairments, so it is challenging for designers to take into account the visually impaired user's needs (Sanchez, 2008). However, integrating UCD approach into a design process for an accessible product can be challenging. Designers are often faced with limited access to the visually impaired population, so UCD methods which could provide most insights from a limited number of participants should be beneficial. Participation in UCD activities could become demanding for the disabled users, so the number and scope of activities should be reasonable and planned to have the user involved just where his or her input is needed. Often, visually impaired users represent just one of the target groups, so the design should also accommodate requirements of the general population, or should be designed according to inclusive design principles.

Visually impaired population considers research of accessibility methods in packaging as one of the top priorities (Van der Geest et al, 2015). However, there is little existing research into applying UCD principles and methods for package design accessible to visually impaired users. In one such study (Barbosa et al, 2018), authors applied Guidance for Project Development procedure, developed by Merino (Merino, 2016) for the development of accessible packaging proposal. They examined several aspect of accessibility of product packaging including methods of opening the package and access to the product.

This paper explores UCD process adjustments in order to establish a user-centred design process which would help designers address most of the challenges they are facing when designing accessible products for people with visual impairments. The process and its' implementation is presented through a case study of designing accessible mould and packaging of bar soap.

\section{CASE STUDY: SOUVENIR SOAP AND PACKAGING DESIGN}

The proposed process was implemented into design of a souvenir soap mould and packaging for the "Soap with dots" (SWD) project for a non-commercial association for people with visual impairments "Martin's cape". The soaps are manufactured by blind and low vision workers. The design requirements 
included that the packaging should be accessible to blind and low vision workers in the process of packaging the soaps and to blind and low vision end users in the process of handling the packaging and accessing the product. Since it has a function of a souvenir, the product should also appeal to users without visual impairments. The design requirements for the soap mould was that it supports more accessible and safer manufacture process for workers with visual impairments. The design should support manufacture of soaps with various surface (relief) designs.

\section{UCD PROCESS FOR PEOPLE WITH VISUAL IMPAIRMENTS}

Since techniques and methods that support user-centred design (Abras, 2004; Maguire, 2001) and contextual design (Beyer et al, 1997; Holtzblatt et al, 2014) are well documented, this paper won't go into their explanation, but rather how they were implemented into the proposed design process.

Inclusion of the user into the design process start with contextual inquiry sessions in the form of semistructured interviews with the users at their workplace, place or residence or the place where the problem occurs (eg. grocery store). Interviewer is followed by an assistant who records what users want, care about and interact with, as well as observations of non-verbal communication (eg. body language). In the interpretation and data consolidation process, affinity diagramming was used to reveal key issues and gain a better understanding of the users and their world. Through persona creation, gained issues were made more actionable and easier for designers to implement through the ideation and validation processes. In the next stage, insights gained from the contextual inquiry are translated into design concepts. In this stage, emphasis is placed on exploring various possibilities and producing a high number of novel design concepts that could address the accessibility issues while at the same time accommodating other design requirements. Rapid prototyping is used to produce low-fidelity functional prototypes of the design concepts. If needed, the low-fidelity prototypes can be supported with 3D visualizations to gain better understanding of the design features.

Since testing a high number of variations could be demanding for the users with visual impairments, but also resource consuming for the development team, informal expert reviews are used to reduce the number of design concepts that will undergo usability testing and user experience evaluation and to determine any major accessibility omissions in the design concepts.

The usability testing is based on completing a set of tasks. Completion time, number of errors, and task completion are measured and observations about participants manipulation with the products are recorded. Moderators should generally avoid assisting the participants while performing tasks. Participants are interviewed after each tested sample for providing deeper insights into their experience. The results from usability testing are used for design selection and refinements, and the process is repeated until the design criteria is met.

After the usability tests, the chosen design concepts are evaluated by users without visual impairments. Measuring user experience is a rather active and expanding field of research, with many evaluation techniques and methods present, but also many problems and challenges still to solve (Hornbæk, 2006). One of the widely used user experience evaluation method, and applicable to the design and production context (Roto et al, 2009), is AttrakDiff (Hassenzahl et al, 2003) - a questionnaire based on the semantic differential method and designed to measure pragmatic and hedonic qualities of interactive products, as well as the product's attractiveness. The most recent version of AttrakDiff evaluation method, AttrakDiff 2 (Hassenzahl, 2004), consists of 28 word pairs which are used to evaluate following dimensions of design: Pragmatic Quality (PQ), Hedonic Quality - stimulation (HQ-S), Hedonic Quality - Identity (HQ-I) and Attractiveness (ATT). Decisions on the final design are based on the results of both usability testing and subjective evaluation.

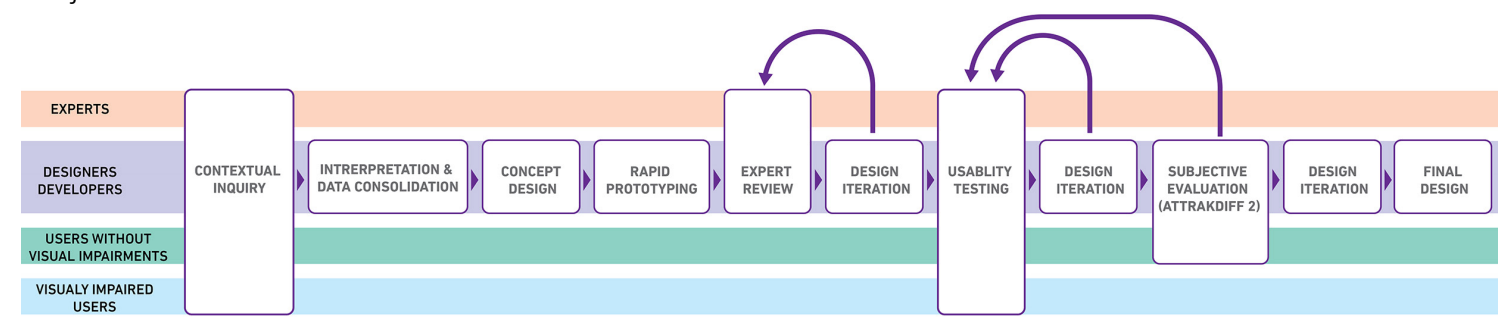

Figure 1: Proposed User-Centred Design process for people with visual impairments 
Since the mould for soap manufacture is a speciality product developed primarily for blind and low-vision users and the visual aspect of the product isn't relevant, process for designing the mould was modified and didn't include subjective evaluation of visual features.

\section{SOAP MANUFACTURING MOLD DESIGN PROCESS}

The design process began with conducting contextual inquiry with the blind and low-vision manufacture workers. A total of 3 participants were interviewed. The interviews were focused on the current process of the bar soap manufacturing and key issues for the blind and low vision workers. It was identified that the existing generic moulds for manufacturing of the soap that are widely available aren't suitable for use. They are made from rigid polymers and usually feature multiple slots that cannot be separated. Since the soap mass is heated to $70^{\circ} \mathrm{C}$ during the casting, difficulties with manipulating the moulds could lead to injury of the worker. Separating the soap from the mould after casting was stressed as one of the most important challenges to workers in the production process. Participants also indicated problems with manufacture of multi-layered soaps with existing moulds.

Based on the insights gained from the contextual inquiry, a concept of a modular mould was developed to aid the users in easier separation of the soap and the mould (Figure 2). The design featured a movable bottom plate which enables easier soap extraction from the mould. The plate is interchangeable and can feature different embossed designs for producing soaps with relief features on the top surface. Rapid prototyping method was used to build a functional prototype of the design. The prototype was created by fused deposition modelling (FDM) 3D printing technique (Figure 3).

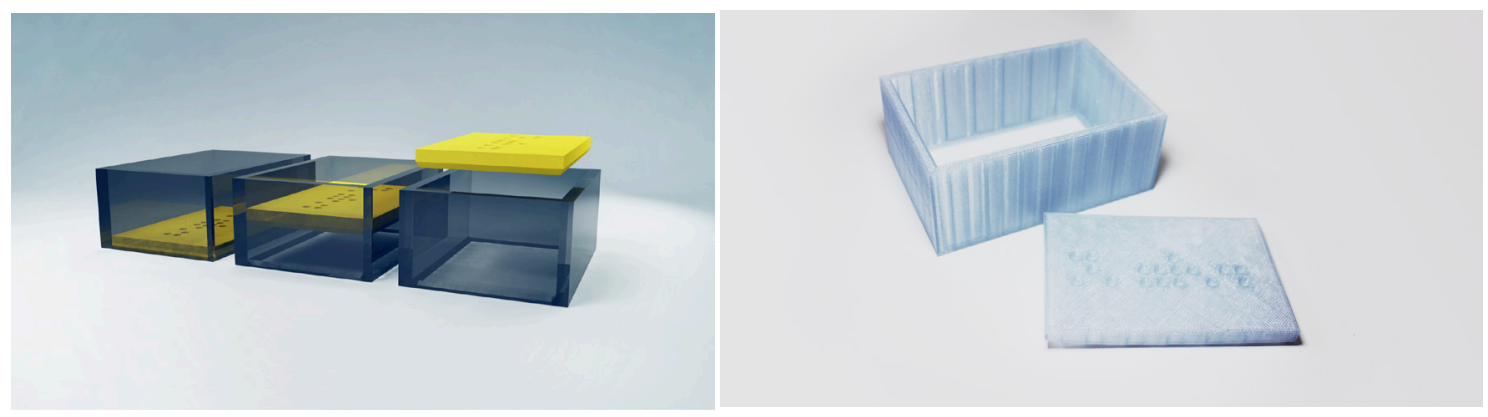

Figure 2: Visualization of the modular mould design

Figure 3: 3D printed prototype of the mould design

In the next phase, usability tests were conducted with the developed prototype. The mould was tested with 3 participants without vision deficiencies in the soap production facility. Usability test results indicated problems with the plate separation from the rest of the mould. Problems were addressed in the next iteration of the design and a new 3D printed physical prototype was created for usability test on the target audience.

Usability test with the participants from the contextual inquiry showed no significant problems with using the proposed modular design of the mould. After establishing the final design, a version of the mould for production of multi-layered soaps was developed (Figure 4). Two usability tests, first with the workers without visual impairments and after with low vision workers, were conducted to validate the developed design.

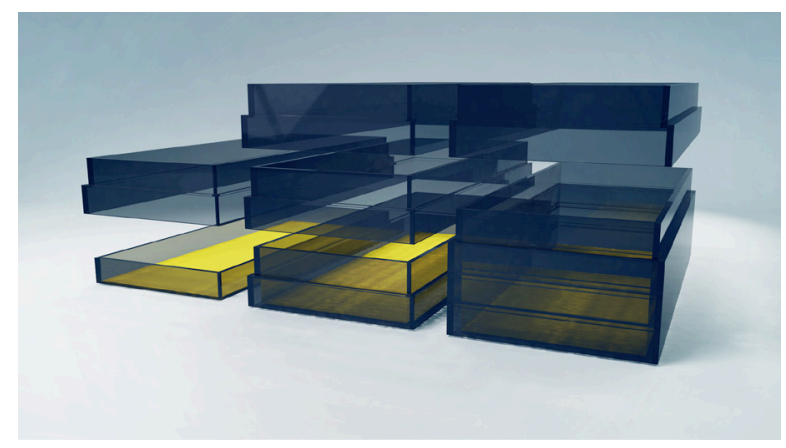

Figure 4: Variant of the mould design for manufacture of multi-layered soaps 


\section{SOAP PACKAGING DESIGN PROCESS}

Contextual inquiry was used to gain insights into everyday interaction of blind and low vision users with packaged goods, with an emphasis on handling of the bar soap packaging from the perspective of the end user and from the perspective of the soap manufacture worker. Participants were asked to provide elaborate comments for the bad and good examples of existing packaging design practices in regard to accessibility for blind and low-vision users, as well as to provide their ideas for enhancement of the existing packaging designs. The interviews were conducted in two sessions, one week apart, with 1 blind and 6 low-vision participants.

All insights were categorized and analysed prior to concept design phase. Participants singled out wrapped packaging as the most difficult to open, as well as most difficult to package the product into. Shrink wrapped cardboard packaging was also found to be impractical to open due to lack of tactile features. Braille lettering was stated as helpful for identifying the content of the packaging and other relevant information, but it was stated as unnecessary for indication of the opening area on the packaging. According to participant insights, a simple tactile feature, such as a dot, notch or a tab on the cardboard box lid would be a sufficient pointer to a blind or a low-vision user.

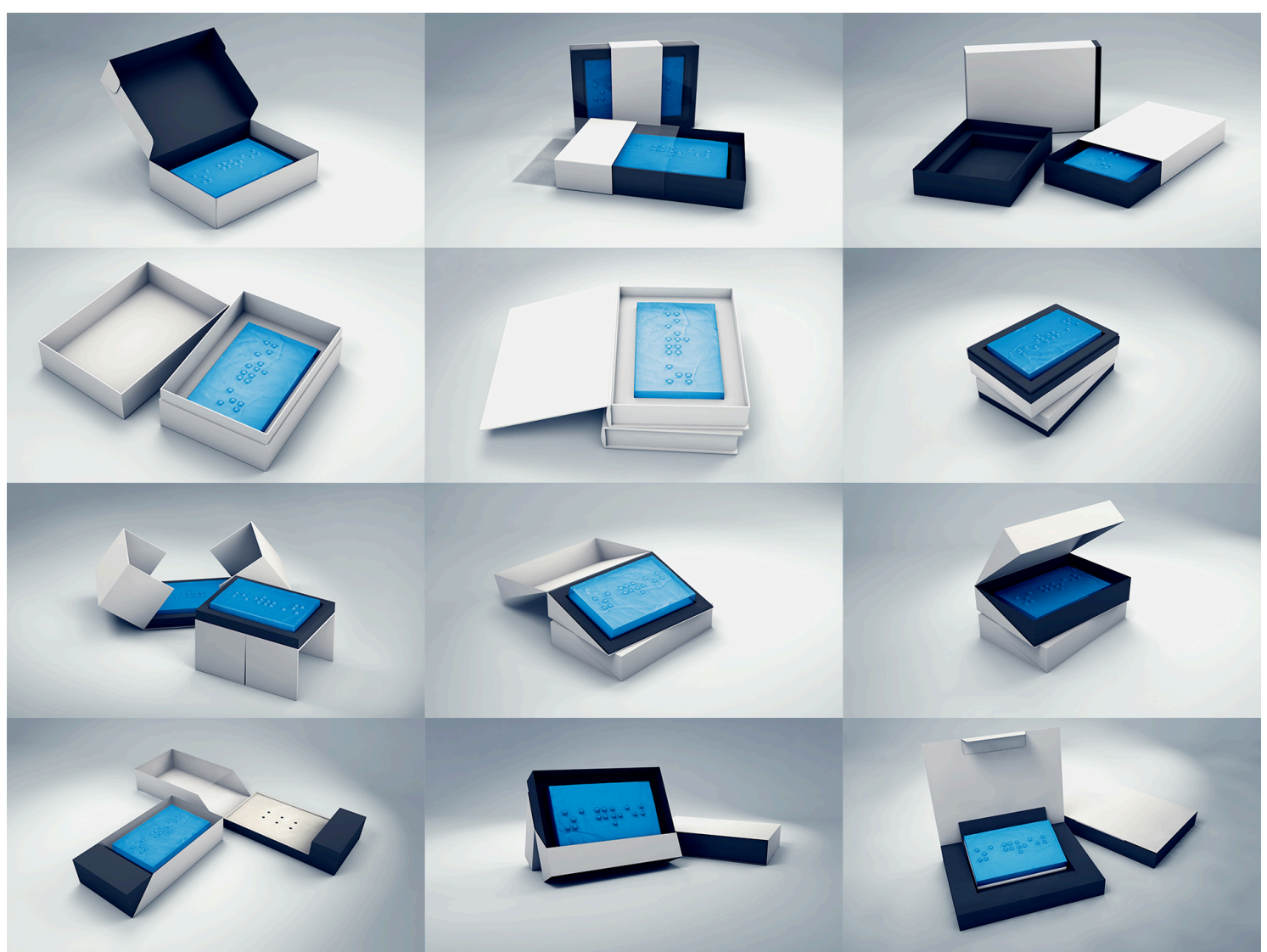

Figure 5: Initial design concepts

Insights were used to develop 12 different bar soap packaging concepts by using rapid prototyping method in combination with 3D visualizations (Figure 5). Functional cardboard prototypes were created on Zünd M-800 digital flatbed cutter. Expert review was conducted to narrow the number of samples that are going to be tested to 5 samples (Figure 6). The chosen designs were modified according to the reviewers feedback. Functional prototypes of the modified designs were created for the purpose of testing with users. Sample 1 and 2 presented a more traditional approach of the carboard box design for bar soaps, while Samples 3, 4, and 5 presented a more novel approach. All designs had accessibility features for easier opening and access to the product. 


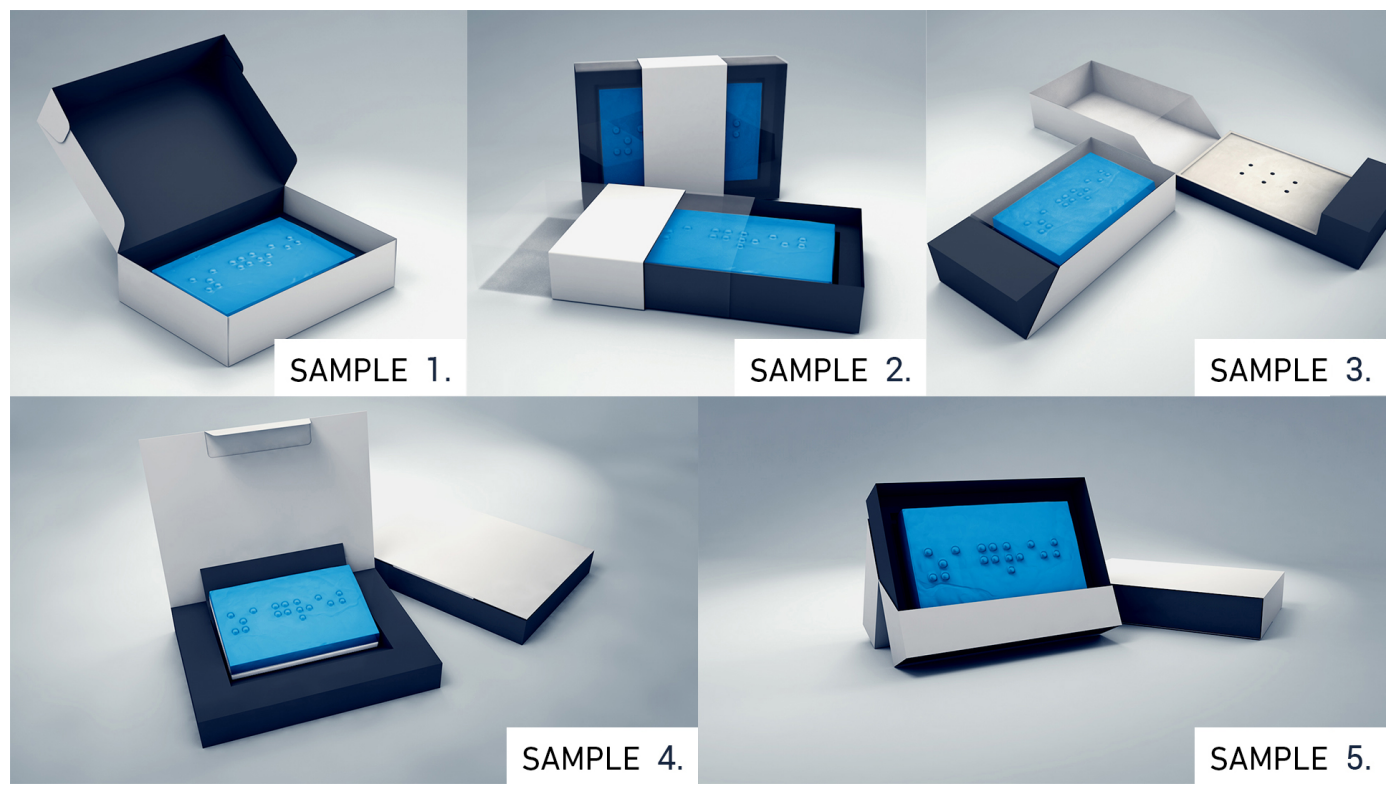

Figure 6: Selected design samples after the expert review process

Usability testing was conducted on 7 users that participated in contextual inquiry. Both the tasks of opening the packaging and packaging the soap into the cardboard box were tested. Observations about the speed of conducting the tasks, errors while conducting the tasks and the way users manipulated with the packaging and the product during the tasks were recorded. After each task, participants were asked to evaluate the packaging in regard of ease of use and accessibility features, as well to identify any pain points in their experience while performing given tasks.

Samples 1 and 3 had weak usability results, with Sample 1's design being especially problematic during the action of closing the box, due to presence of flaps that needed to be tucked into the designated spaces. Samples 2, 4, 5 were found to offer similar level of usability, with the participant's slight preference toward Sample 4.

After usability testing with blind and low-vision users, a subjective evaluation was conducted with users without visual impairments. The evaluation is conducted on cardboard prototypes of 5 Samples. All Samples featured identical colour and surface properties of the material used to eliminate their influence on the results. 20 participants evaluated each of the Samples by semantic-differential questionnaire which featured 28 word-pairs from AttrakDiff method and a 7 point Likert scale for each word pair. The research was conducted in a controlled environment and each sample was presented on a neutral background and in the same lighting conditions.

Results show that Sample 1 was rated lowest compared to the rest of the samples in regard to all dimensions of quality and attractiveness (Figure 7). Sample 2, while having the similar results for pragmatic quality compared to Sample 4 and 5, has scored low for the hedonic quality dimensions and attractiveness. Sample 5 had the best results for both hedonic quality dimension and attractiveness, with Sample 4 receiving the second highest scores. However, although being perceived as best design overall, Sample 5 was rated as the most unpredictable and cumbersome design (Figure 8).

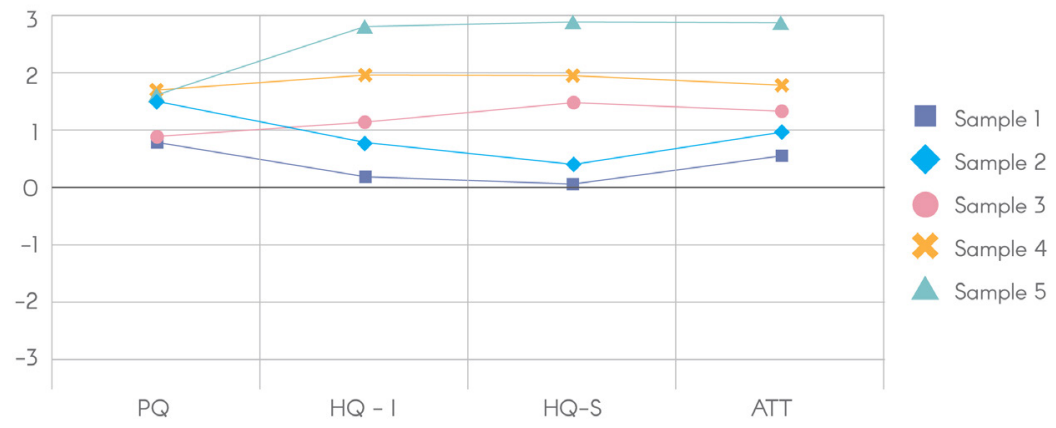

Figure 7: Graph of the mean values for the AttrakDiff subjective evaluation results for each of the quality dimensions 


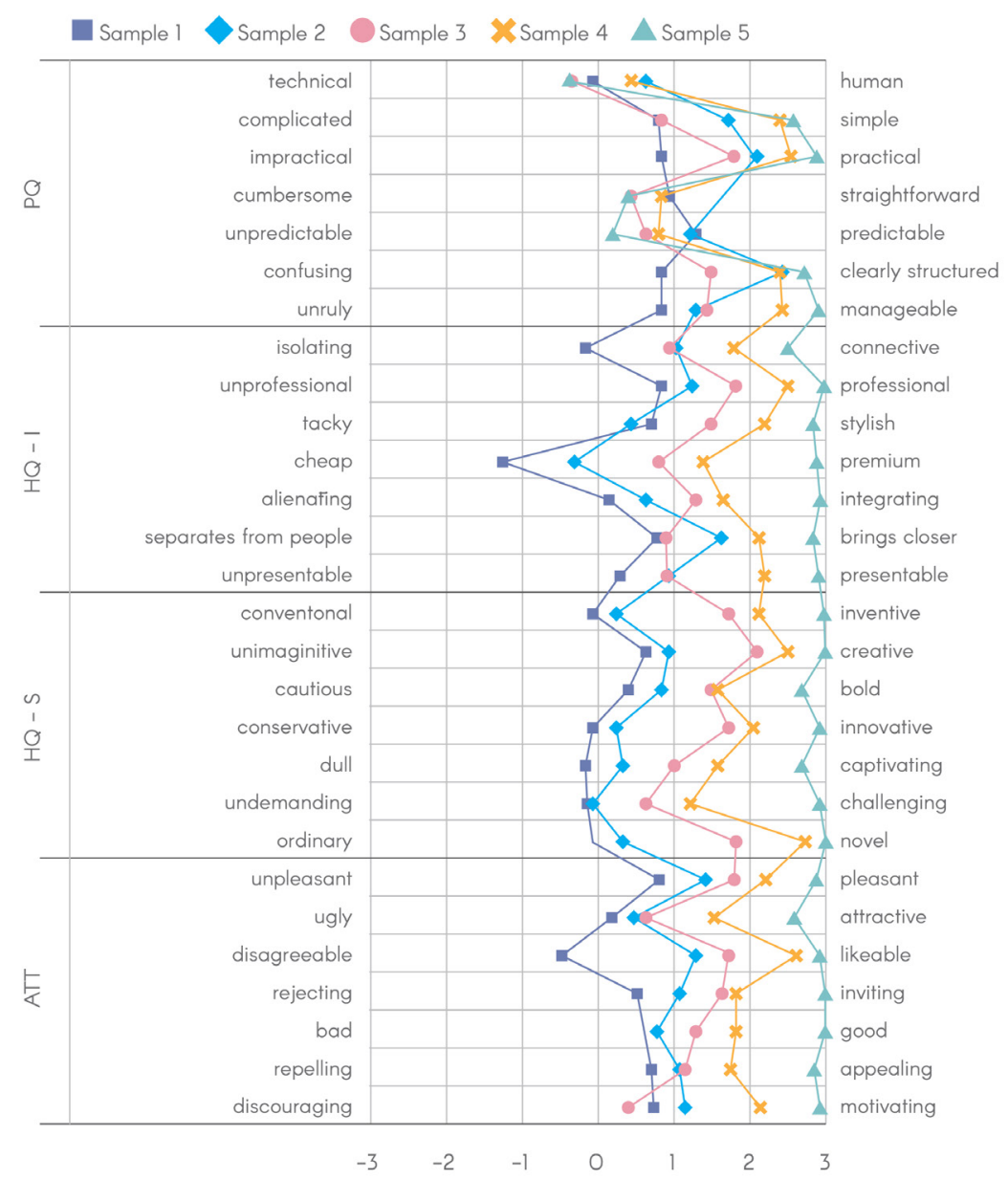

Figure 8: Graph of the mean values for the AttrakDiff subjective evaluation results for each word pair

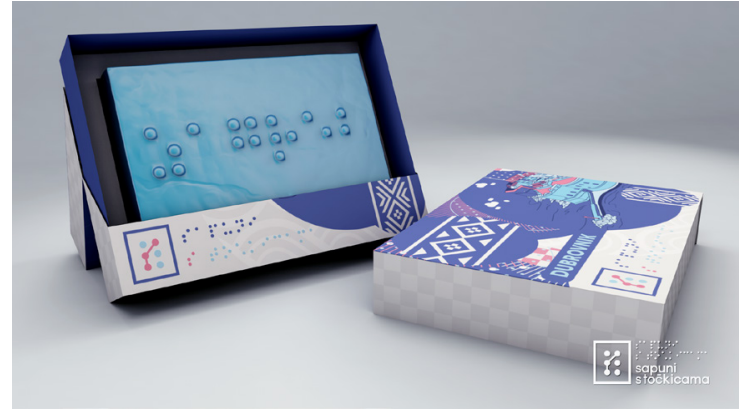

Figure 9: Visualization of soap design and visual appearance of the packaging based on Sample 5

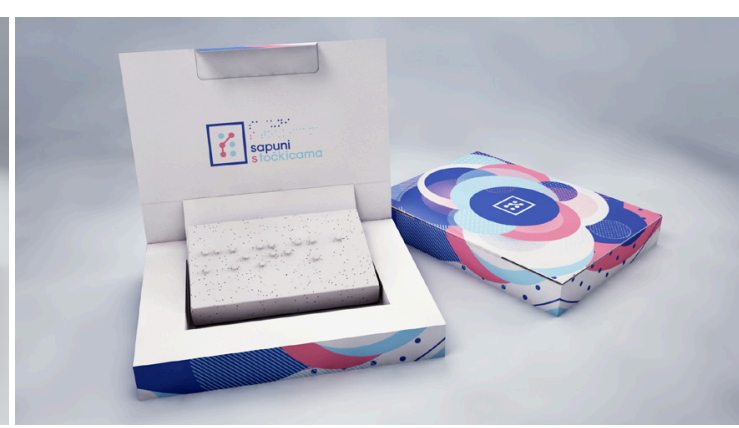

Figure 10: Visualization of soap design and visual appearance of the packaging based on Sample 4

Based on the results of usability testing and AttrakDiff 2 evaluation, the manufacturer opted to use two packaging designs, Sample 4 and Sample 5, for its' soap product range. The visual identity for the product and packaging was created and applied to packaging designs, as well as the range of soap designs manufactured with the developed moulds (Figure 9, 10).

\section{CONCLUSION}

Designing physical products accessible to people with visual impairments still presents a significant challenge to many designers. The inclusion of users in the design process is a necessity, but can introduce several challenges, so the selection of the techniques and methods should be optimised. The proposed User-Centred design process for people with visual impairments was successfully applied to the case of designing packaging of accessible packaging for souvenir bar soap manufactured by blind and low-vision 
users. Further research is needed to develop subjective evaluation methods for user experience measurement more suited to the users with visual impairments, so they can be included in the relevant phases of the proposed design process.

\section{REFERENCES}

[1] Abras, C., Maloney-Krichmar, D., Preece, J.: "User-centered design", Encyclopedia of HumanComputer Interaction, Sage Publications, Thousand Oaks, 2004.

[2] AlZuhair, M. S., Najjar, A. B., Kanjo, E.: "NFC based applications for visually impaired people - A review", Proceedings of IEEE International Conference on Multimedia and Expo Workshops (ICMEW, Chengdu, 2014), pages 1-6. doi: 10.1109/ICMEW.2014.6890657.

[3] Barbosa, M. L. de A., Ribeiro, G. Y. A., Soares, I. G., Okimoto, M. L.: “Accessible Packaging: A Study for Inclusive Models for Visual Impairment People", Proceedings of the AHFE International Conference on Ergonomics in Design 2018, (AHFE, Orlando, Florida,2018), pages 282-292.

[4] Beyer, H., Holtzblatt, K.: "Contextual design: defining customer-centered systems", (Elsevier, San Diego, 1997).

[5] Van der Geest, T. M., Buimer, H. P.: "User-centered priority setting for accessible devices and applications", Proceedings of Mensch und Computer 2015 - Workshopband, (Mensch und Computer, Oldenbourg: De Gruyter, Stuttgart, 2015), pages 383-389.

[6] Hassenzahl, M.: "The Interplay of Beauty, Goodness, and Usability in Interactive Products", HumanComputer Interact 19(4), 319-349, 2004. doi: 10.1207/s15327051hci1904_2.

[7] Hassenzahl, M. , Burmester, M. , Koller, F.: “AttrakDiff: Ein Fragebogen zur Messung wahrgenommener hedonischer und pragmatischer Qualität", Proceedings of Mensch und Computer 2003, (Mensch und Computer, Verlag, 2003), pages 187-196.

[8] Holtzblatt, K., Beyer, H.: "Contextual Design: evolved", Synth. Lect. Human-Centered Informatics 7(4), 1-91, 2014. doi: 10.2200/S00597ED1V01Y201409HCI024.

[9] Hornbæk, K.: "Current practice in measuring usability: Challenges to usability studies and research", International Journal of Human-Computer Studies 64(2), 79-102, 2006. doi:10.1016/j.ijhcs.2005.06.002.

[10] Maguire, M.: "Methods to support human-centred design", International Journal of HumanComputer Studies 55(4), 587-634, 2001. doi: 10.1006/ijhc.2001.0503

[11] Merino, G. S. A. D.: “Guia de Orientação para Desenvolvimento de Projetos: Uma metodologia de Design Centrado no Usuário", (NGD/UFSC,Florianópolis, 2016).

[12] Roto, V., Obrist, M., Väänänen-Vainio-Mattila, K.: "User experience evaluation methods in academic and industrial contexts", Proceedings of ACM CHI 2009 (CHI, Boston, 2009).

[13] Sanchez, J.: "User-Centered Technologies for Blind Children", Human Technology- An Interdisciplinary Journal on Humans in ICT Environments 4(2), 96-122, 2008. doi:10.17011/ht/urn.200810245832.

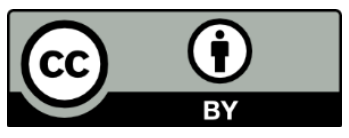

(C) 2018 Authors. Published by the University of Novi Sad, Faculty of Technical Sciences, Department of Graphic Engineering and Design. This article is an open access article distributed under the terms and conditions of the Creative Commons Attribution license 3.0 Serbia (http://creativecommons.org/licenses/by/3.0/rs/). 